\title{
The Dilemma of Fiat in the Local:Legal Currency Reform of Guangdong Province
}

\author{
LaoKaizhun* \\ Department of history, Jinan University, Guangzhou,China \\ laokaizhun@163.com
}

Keywords: Lowercase letters. Legal currency reform ,Guangdong ,exchange rate.

\begin{abstract}
The fiat implement of national government was reformed in 1935, at the same time, Guangdong's government was implementing the local currency. After the June 1st Incident of 1936, the national government was adjusting Guangdong's policy by sending financial staff to rectify financial ,to consolidate the currency credit, to establish currency reserves gradually, and to recovery the local money system. The national and local government have controversy on the problem of the exchange rate between local currency and fiat. The fate of fait currency in Guangdong was the result of policys and also reflecting the complexity of fiat reform.
\end{abstract}

\section{法币在地方的困境：广东法币改革}

\author{
劳开准 \\ 暨南大学历史系, 广州, 广东, 中国 \\ laokaizhun@163.com
}

关键词：法币; 改革; 广东; 汇率

中文摘要:国民政府1935年实行法币改革, 全国推行统一的货币, 广东推出本地纸币。两广事 变, 广东还政于中央, 国民政府对广东人事进行改组, 派人到广东整顿金融, 巩固广东倾向 的信用，逐渐建立货币发行准备金，收回广东地方纸币。围绕广东银毫券与法币之间的汇率， 中央政府与广东当局展开了激烈的争论。法币在广东的遭遇反映了政局变动, 显示了货币改 革的复杂性。

\section{1. 引言}

1935年国民政府实行法币改革，在金融史上具有里程碑意义，实现了从金属货币到纸币 转变, 解决了金属货币因成色、重量不一而难以结算的问题。货币改革不只是经济方面的问 题，与政治、军事、文化等交织在一起，从而更加复杂。有关法币改革的研究比较深入 ${ }^{1}$, 至 于广东法币改革的研究, 目前还是比较薄弱。2本文试图从中央与地方两者的互动来考察 1935 年广东法币改革进程以及所遇到的问题，探讨法币改革在地方上的推行情况。

\footnotetext{
1 代表论著有: 卓遵宏的《中国近代币制改革史1887-1937》（台北: 国史馆2009年）、姚会元的《论法币改 革》（《学术月刊》1997年第5期）、尹全洲的《论中国的法币改革》（《宁夏社会科学》2001年第2期）、吴 景平的《蒋介石与1935年法币政策的决策与实施》（《江海学刊》2011年第2期）等。

2 张连红的《整合与互动: 民国时期中央与地方财政关系研究1927-1937 》（南京师范大学1999年版）、张晓辉主编的《民 国时期广东财政政策变迁》（经济科学出版社2011年版）在研究财政问题时研究了广东法币改革问题。曾涛《三十年代广东
} 


\section{2.中央控制弱化下的广东货币}

广东政局变动频繁，历届政府发行的货币不一，以致市场上流通的货币多种多样，既有 金属货币又有纸币。金属货币有银元、毫银，毫银为流通的主要货币，特别是双毫（即2角银 币）一度作为广东的主要通货。当时各银行发行的纸币，亦以毫银为单位，称银毫券。3法币 改革之前，广东发行纸币的主要有两家银行：广东省银行、广州市立银行。

南京国民政府成立后, 为统一货币而做出努力, 广东的半独立状态的存在使得中央政府 推行的政策效果甚微。1927年11月1日，南京国民政府另立中央银行，要求广东的中央银行改 为广东分行。广东当局不愿放弃财政权，以该行为孙中山所创，拒不改名。1924年8月15日， 孙中山在广州创立中央银行, 宋子文担任银行行长。宋子文为了维护该行的信用, 不滥发纸 币, 反对随意垫借军费。4这一政策很快被现实的革命需要打破, 无论是东征还是北伐都需要 大量经费。随着北伐节节胜利, 其货币的发行也随之到长江流域, 身价比大洋券还高, 钞票 回笼，广东的负担很重。5货币发行过多，以致影响货币信用。

1928年7月，国民政府召开第一次全国财政会议，就货币统一问题进行了讨论，审议了《地 方银行案》、《国币条例及实行细则案》等有关货币问题提案, 提出地方银行无发行纸币之 权，国币应统一，速办国家银行。6会议通过后，经行政院颁布，要求各地政府执行。广东当 局以在广东的中央银行为招牌, 继续发行货币。南京另立中央银行之后, 在广东的中央银行 实际上已经失去了中央银行的作用, 但其毕竟仍以中央银行的面目继续存在, 广东当局仍以 此为由漠视中央的政策。

1929年1月25日，财政部呈行政院，地方银行不得发行钞券。除了在广东的中央银行外， 其他银行仍我行我素，继续发行纸币，把中央的政策当成耳边风。1929年7月23日，财政部就 华南各银行发行钞票一事发文，印制钞票需呈财政部核准后方可。7实际上，此发文和以前的 一样，根本没有起什么效果。同年3月1日，在广东的中央银行改组为广东中央银行。

1932年1月1日，在广东中央银行基础上改组，成立广东省银行。1932年9月27日，陈济棠 在西南政务委员会上提出《广东省三年施政计划提议书》, 提出 “发展省立银行, 使能为全 省金融之重心，并藉省立银行之资力，发展种种建设事业。” 8 陈济棠对广东省银行的发展寄 予了厚望。1933年，广东省政府、广东省银行、广州市立银行共同担保广东省建设厅借用庚 款。9 广东省银行成立之后, 确实为广东经济做出了贡献, 仍旧是广东当局控制财政的工具。

广东当局以广东省银行、广东市立银行作为载体，滥发纸币。1934年，第二次全国财政 会议再次讨论了各省私设银行及擅自发纸币问题。南京国民政府对地方银行进行了整顿，但 各地擅自发行纸币的问题仍旧是一个顽疾。1935年1月28日，财政部长孔祥熙提出取消各银行 发行权的提案, “经旧财政部核准迄未开始发行各行号之发行权, 概以取消。其已停业清理

统一币制前后》（《广东金融》1990年第10期）、王丽《走向 “统一” 的广东省货币金融一国民政府法币改革的区域性案例 分析》 (《暨南大学学报》2014年第10期) 专门研究了广东法币。

3 广东省地方史志编纂委员会编: 《广东省志・金融志》，广东人民出版社1999年版，第54页。

4 张晓辉主编: 《民国时期广东财政政策变迁》，经济科学出版社2011年版，第134页。

5 李毓澍访问、周道瞻记录、郭廷以校阅: 《余汉谋先生访问录》, 《“口述历史” 第7期: 军系与民国政局》, 台北: 中央研究院近代史研究所1996年，第214页。

6 金融组: 《审查银行币制各案报告书》，全国财政会议秘书处编：《全国财政会议汇编》（1），台北: 文海 出版社1987年版，第137-138页。

7 中国第二历史档案馆编：《中华民国史档案资料汇编》第5辑第1编 “财政经济” 卷 (4)，江苏古籍出版社1994 年版，第575页。

8 陈济棠: 《广东省三年施政计划提议书》, 广东省档案馆编印: 《陈济棠研究史料（1928-1936）》, 1985年, 第138页。

9 《广东省政府、广东银行、广州市立银行会同担保广东省建设厅借用庚款证书》（1933年），广东省档案馆 藏，广东省建设厅档案，006-002-0602-104。 
各行号，嗣后虽呈准复业，亦不得再有发行”。10提案经行政院第197次会议决议通过，并于 1月30日以行政院指令财政部遵照执行。南京国民政府、中央银行多次命令地方银行不得发行 纸币, 此种命令只在南京政府控制的地区有效。广东处于半独立状态, 仍自行发行纸币, 发 行量还不受准备金的限制，随意发行，以致纸币泛滥，金融市场不稳。1935年1月22日，广州 市立银行出现挤兄现象。为了稳定市面, 第 1 集团军总部拨出 20 万元、广东省政府拨 20 万元、 广州市政府拨 30 万元, 并向外国银行借款 130 万元作为维持广州市立银行凭票的基金。 ${ }^{11}$ 此做 法固然能解燃眉之急, 然滥发纸币的根本问题没有解决, 广东的金融市场难以稳定。1935年8 月, 广东省银行发行总额达 4000 万元左右, 广州市立银行发行额为 150 万元左右, 其所发行 的5元、10元刚恢复兑换不久, 市价尚低于币面价值。12广东当局滥发纸币导致纸币贬值, 金 融市场混乱。

广东政局动荡，各届政府发行的货币不一，这不仅是广东传统、经济水平、人们的使用 习惯导致, 更为深层的原因是改革不彻底引发的劣币驱逐良币。13改革不彻底又是政局造成 的。南京国民政府成立之后, 只是在形式上统一了中国, 广东仍维持着半独立的状态。中央 政府的在广东推行的政策要以不损害广东当局的利益为前提, 一旦有损广东当局利益, 就遭 到广东军政当局的强烈抵抗。广东当局正是通过把持广东地方的财政, 掌控地方财政命脉, 与中央争权。

\section{3. 中央与广东的法币政策}

国际金融市场的动荡更是加剧了国内金融危机。国外白银价格上涨，白银外流，汇价上 升, 物价低落。1934年10月15日, 国民政府征收白银出口税和平衡税。征收白银出口税目的 是防止白银外流、限制银价汇率上涨, 从而使出口白银无利可图。“此种举措, 因能收效于 一时, 究非根本安定金融之方案。” 自征收白银出口税后, 世界银价继续上涨, “汇率与银 平价之差额高达百分之十五至百分之六十不等”。14巨大的利润空间, 一些不分商人铤而走 险，白银走私严重。从1934年7月起，仅3个半月的时间，中国白银流出就达2万万元以上。15 广东邻近香港, 白银走私更加严重。1935年, 美国抬高白银价格, 广州一些银号走私白银到 香港。广东私运出口的白银年达2000多万元。16中国以白银作为货币, 白银不足, 白银走私 使得中国货币市场更加动荡不安。

为防止白银外流，实行法币政策，实行白银国有。1935年11月3日，财政部发布实施法币 公告, 从11月4日起, 以中央、中国、交通银行发行的钞票定为法币, 所有完粮、纳税及一切 公私款项的收付使用法币, 不得使用现金, 违者全数没收。除这三家银行外, 经财政部核准 发行的银行钞票, 其发行数额以截至 11 月 3 日止流通总数为限, 不得增发, 逐渐以中央钞票换 回, 未发之新钞回收的旧钞, 悉数交发行准备管理委员会保管。任何银行、商店、个人等所 持银类自11月4日起, 交由发行准备管理委员会或指定银行汇换。财政部同时公布《发行准备 管理委员会章程》，以巩固法币信用。当天，孔祥熙为发行法币致电省政府主席、各市市长、

\footnotetext{
10 中国第二历史档案馆编: 《中华民国史档案资料汇编》第5辑第1编 “财政经济” 卷 (4), 江苏古籍出版社1994 年版，第36页。

11 广东省地方史志编纂委员会编: 《广东省志・金融志》, 广东人民出版社1999年版，第18页。

12 中国人民银行总行参事室编: 《中华民国货币史资料1924-1949》第2辑, 上海人民出版社1991年版，第 232 页。

13 张小杰: 《广东 “银毫券” 的兴亡》, 《中国钱币》2014年第3期。

14 孔祥熙: 《十年来的中国金融与财政》, 中国文化建设协会编: 《抗战前十年之中国》 (1), 台北: 文海出 版社1974年，第95页。

15 中国第二历史档案馆编：《中华民国史档案资料汇编》第5辑第1编 “财政经济” 卷 (4)，江苏古籍出版社1994 年版，第316页。

16 郡仲池: 《收购白银前后忆述》, 广州市政协文史资料研究委员会编: 《南天岁月一陈济棠主粤时期见闻实 录》，广东人民出版社1987年版，第314页。
} 
各司令、绥靖主任, 希望得到他们的支持。军事委员会委员长蒋介石给各行营主任、各绥靖 主任、各总司令、各路总指挥、各军长、各师长发表通电, 要求切实协助财政部整顿币制, 对各银行严密保护。17蒋介石继孔祥熙之后给各地军事负责人发电, 希望这些军事长官支持 政府部门的工作, 这是很少见的。政府政策在地方能否得到落实, 很大程度上是在各地掌握 军权的人。依靠军权而控制党国的蒋介石自然十分清楚这一点。蒋介石给各地军人电令, 足 见蒋介石此次十分重视, 希望得到地方军人的支持。

广东当局并没有因蒋介石的态度而改变。实施法币政策之前, 财政部长孔祥熙派人到广 东协调货币统一问题。广东当局并没有表态。然而, 一旦国民政府法币政策出台, 广东当局 则马上采取对策。1935年11月6日，陈济棠、林云陔、区芳浦等召开紧急经济会议，实施货币 管理办法: “（1）自本年11月7日起, 以广东银行之银毫券、大洋券、及广州市立银行之凭 票为法定货币, 所有完粮纳税, 及一切公私款项之收付, 概以法币为限, 不得行使现金, 并 不得私藏隐匿, 以防白银之偷漏, 如有私运出口者, 应照危害民国紧急治罪法处治。（2）法 币准备金之保管及其发行事宜由政府人民共同组织发行准备管理委员会办理, 以示公开, 而 昭公信, 委员会组织章程另定之。（3）本办法公布后, 所有银毫大洋已失其通货之效用, 自 应由政府全数收回, 交委员会保管。凡银行银号商店, 及公私机关, 或个人所有之银毫或大 洋, 应自11月7日起, 交由广东省银行总行, 及其所属分支行, 办事处, 兑换所, 暨广州市立 银行, 或其他指定机关兑换, 毫券银毫加二给值, 大洋加四四给值, （银毫 1 圆换毫券 1 圆 2 毫，大洋 1 圆换毫券 1 圆 4 毫4仙）其行使大洋区域，收换大洋照面额加二，以大洋券付之。（4） 凡属银类, 如银条银砖银饼等, 自11月7日起, 应交由广东省立银行按照成色计值收买, 不得 私藏。（5）凡11月6日以前, 所有以银币单位订立之契约, 应各照原定数额, 于到期日, 概 以法币结算收付之。（6）凡属人民存有之外币, 得自由买卖, 以应外汇之需求, 但不得直接 行使。” 18

广东当局在法币政策公告之后，制定广东特色的货币管理办法。从这6项货币管理的具体 办法来看，每一项都是针对中央法币政策而制定的，地方保护主义特别严重，目的就是为了 维持广东地方货币。广东当局制定的应对政策，立即引起了广东金融动荡。广东货币管理6 项办法颁布的第 2 天, 银行银业公会、众私盘一律停顿，银号将外币、金元、金业等价格极力 抬高, 金融极混乱。日本银行乘机破坏, 派人高价收购白银, 以致广州白银飞涨, 法币大跃。 19 这显然是广东当局没有想到的。

广东当局继续寻找解决保留广东地方货币的办法。1935年11月9日，陈济棠组织 “广东法 币发行准备管理委员会”, 以沈载和、陈佐璇、植子卿等人为筹备委员, 进行筹划发行准备 管理工作。 ${ }^{20} 11$ 月 15 日, 广东省颁布了《广东省法币发行准备管理委员会组织章程》。法币 发行准备管理委员会的组成人员以下: 广东省商会联合会代表 2 人、广州市商会代表 1 人、汕 头市商会代表 1 人、海口市商会代表 1 人、江门市商会代表 1 人、广州市银行同业会行代表 2 人、 广州市银业公会及忠信堂代表各 1 人、广东省银行行长及副行长各 1 人、广州市立银行行长、 广东省财政厅代表 1 人、广东省政府选派金融专家或 1 到 3 人。法币发行准备管理委员会设常务 委员 5 人，除广东省财政厅代表、广东省银行行长为常务委员外，其余 3 人由委员选举。21广

17 中国第二历史档案馆编: 《中华民国史档案资料汇编》第5辑第1编 “财政经济” 卷 (4), 江苏古籍出版社1994 年版，第314-319页。

18 《财部新币说明书》, 秦孝仪主编: 《“革命文献” 第74辑: 抗战前国家建设史料一货币金融》, 台北: 中国国民党 中央委员会党史委员会1978年，第43-44页。

19 中国人民政治协商会议广东省广州市委员会文史资料研究委员会编：《广州百年大事记》（下），广东人民 出版社1984年版，第472页。

20 邵仲池: 《收购白银前后忆述》, 广州市政协文史资料研究委员会编: 《南天岁月一陈济棠主粤时期见闻实 录》，广东人民出版社1987年版，第315页。

21 《广东省法币发行准备管理委员会章程》，《广东省政府公报》1935年第313期，1935年11月20日，第53-54 页。 
东当局拉笼商会、行业协会, 以此来结成一个联盟, 同时通过广东的商会、行业协会的影响 到提高准备管理委员会的信誉。1935年12月28日, 广东省法币管理委员会成立, 委员沈载和 熊少康等15名委员宣誓就职。22广东省政府通过成立发行准备管理委员会, 把商界中有影响 力的人纳进来, 通过各商业团体、领袖的影响来巩固广东本地货币的信用, 这使得法币在广 东推行遇到的阻力加大。

\section{4. 法币在广东确立}

为解决广东的财政问题，中央政府与广东当局就币制改革问题进行了会谈。1936年4月， 财政部派高等顾问兼江海关监督唐海安到广东商谈币制改革的具体问题。在白银移交中央保 管问题上没有达成共识, 广东以白银移中央保管难以办到, 广东法币委员会派人赴香港建造 大银仓, 用以保管广东省存银。唐海安愤气离开广东, 广东法币改革因此搁浅, 原来计划到 广东整理金融的交通银行总经理唐寿民、中国银行经理贝祖诒两人中止南行。23中央与广东 的法币改革谈判陷入了僵局。国民政府等待解决广东法币问题的时机。

1936年5月12日，胡汉民因脑溢血突然逝世。蒋介石派王宠惠、居正等8名委员到广东吊 丧, 乘机向陈济棠提出解决西南问题的5项条件包括统一币制。24与此同时, 孔祥熙再派唐海 安到广东进行商谈。5月18日，唐海安与陈济棠、广东省主席林云陔、财政厅长区芳浦等人见 面, 继续商谈币制改革问题。陈济棠、林云陔以广东币制非常复杂, 必须找到解决各种难题 之后才能接受法币制度。广东当局对国家统一货币表示赞同，只是时间问题。5月26日，居正 等 8 人会见了陈济棠、林云陔、李宗仁、白崇禧等人, 就统一问题进行商谈。255月29日, 唐 海安与陈济棠之兄陈维周见面, 商量解决广东外汇问题的办法。

1936年7月9日, 唐海安再次与陈济棠详谈。唐海安认为陈济棠对没有得到南京的谅解很 消极, 请中央派要员来慰问, 希望孔祥熙尽快派唐寿民、贝祖诒等人来广东。广东大致接受 币制改革，具体问题还需要商量。唐海安与区芳浦商谈货币改革具体问题，没有达成一致。 关于改制损失方面, 财政部答应拨 500 万元，广东省则要求拨 1000 万元。至于白银保管问题方 面, 双方分歧很大, 广东省不愿移白银中央保管。唐海安见商谈无果便离粤赴港。到香港后, 唐海安在报纸上揭露广东当局的做法。广东法币不受四六准备金约束，广东省所存现金不过 9000 余万元，而发行纸币已超过20000万元以上，按照法币应缴六成准备金计算，还差3000 万元。广东法币准备金不足, 广东当局将毫券银准备金由杨建平出面销售给外商, 广东法币 管委会运 10000 万元到香港储存。26消息一出, 广东纸币大跌。唐海安因此被陈济棠派人监视, 对陈济棠的做法十分恼火, 并写信给中央表示对陈济棠的不满。

随着广东政局的变动, 中央调整了广东人事，从而改变了广东财政独立的局面。1936年7 月18日, 陈济棠通电下野, 蒋介石改组广东军政当局, 派人到广东整理财政。7月19日, 孔祥 熙对唐海安表示慰问, 派宋子良为广东省财政特派员兼财政厅长。7月20日, 蒋介石给孔祥熙 电, 要求财政部派专员从香港到广东, 筹划财政计划, 并准备临时接济余汉谋总司令款项, 约再需 300 万元。7月21日, 蒋介石在给孔祥熙的密电中谈到广东财政厅长等职位发表过早, 要叮嘱宋子良等人对广东文武官员要以谦和的态度协调, 不要让广东当局觉得中央有争权夺 位的想法。7月22日，广东省财政特派员兼财政厅长宋子良、财政部次长邹琳、粤桂闽区统税 局局长吴健陶、中央银行业务局副局长周守良等人乘飞机到广东。宋子良等人到韶关时, 会 见了广东绥靖主任余汉谋, 就广东财政问题进行了洽谈。到广州后, 随行人员郝重光就整理

22 《法币管委会成立》，《申报》1935年12月29日，第3版。

23 《唐海安将北返 粤改大洋制已搁浅》，《申报》1936年7月12日，第15版。

24 程思远: 《我的回忆》: 华艺出版社1994年版, 第86页; 刘斐: 《两广 “六一”事变》, 广州市政协文史资 料研究委员会编: 《南天岁月一陈济棠主粤时期见闻实录》，广东人民出版社1987年版，第463页。

25 《谈商团结办法 宁粤要人赴从化》，《申报》1936年5月27日，第3版。

26 《财政部某要人谈粤省滥发纸币，《申报》，1936年7月11日，第3版。 
广东的财政问题发表了讲话, 指出广东法币改革要进行详细调查, 制定方案, 呈请中央、地 方政府核定后逐步实施。27

中央财经人员到广东后，逐渐掌握了广东的情况。1936年8月19日，徐堪等金融专家经过 实地调查, 广东准备金不足 $17 \%$, 认为广东法币改革要谨慎, 不能操之过急。28准备金不足, 仍广东当局之前滥发货币导致，严重影响其实际的价值，广东法币改革缺少大量的资金。

广东法币改革的第一步便要设立中央银行广东分行，发行大洋币 12000 万元。29第二步充 足准备金。由中央、中国、交通三银行运大批法币到广东。 ${ }^{30}$ 此外，中央通过发行公债的方 式来弥补广东准备金的不足。1936年8月, 为整理广东省币制, 增发公债 12000 万元。法币与 毫券的兄换比率由 100:150改为 100:144, 损失约2000万元, 由中央补贴。31这是中央充分考虑 到了广东人民的承受能力, 由全国人民来为广东当局之前滥发纸币买单。毫券可以与法币之 间的兑换比率是由毫券的价值决定的。

汇率之争一直广东法币改革的争议问题。关于中央法币与广东毫券之间的兄换比率, 中央与广东当局有不同的看法, 即便广东当局, 具体主张也不一, 有 100 元法币可换成130元 毫券、144元毫券、150元毫券、157元毫券、177.3元毫券等观点。余汉谋主张不超过130元。 32 余汉谋是考虑广东人民的负担太重, 其主张与广东银业公会、广东商会的看法是一致。1936 年 8 月 11 日, 广州市商会电请蒋介石、孔祥熙大洋与毫券比率不超过 3 。33 大多数广东人主张 加三, 其依据是以往国税的情况, 都没有考虑到毫券的价值。政府最后的决定是加四八, 这 与广东人民的希望有一点差距。政府机关如法院、邮局、粤汉铁路等不遵守法律, 自定为加 五, 这引起人们的怨恨。 ${ }^{34}$ 地方当局在中央政府推行法币改革之际, 运用手中权力来谋取利 益。广东地方当局从地方的小团体利益出发, 尽力主张降低汇率, 更为严重的是地方当权者 利用权力, 借机私下调高汇率, 以谋取个人的利益。1936年8月27日, 财政部回复广州市商会, 加三兑换不准, 并指出毫券贬值, 财政部筹准备金以稳固毫券的信用。35广东当局对中央的 回复并不满意，与广西相比感到不平。1936年11月6日，广东省请求财政部修改法币与毫券的 兄换比率。36汇率之争一直是广东法币改革存在的焦点。中央考虑到了广东的实际, 先是稳 定广东纸币的信用, 在巩固广东纸币信用的基础上推行法币。广东当局主张越低越好, 是从 广东的地方利益出发, 没有从毫券的实际价值出发。法币与毫券的汇率既不能过高也不能过 低, 过高则会加重广东人民的负担, 过低的话则会给损害法币的统一。这是中央与广东当局 都意识到的问题。汇率之争, 实则是中央与地方的权力之争。

国民中央政府借助实行法币政策，统一财政，从地方手中收回财政权。1936年8月28日， 广东省财政厅下令广东省立银行、广州市立银行发行的毫券并非法定货币, 不得再沿用法币 字样，可称省毫券或市毫券。37在广东的毫券不再是法币，作为纸币仍继续使用。中央政府 在不动摇中央法币的信用之下, 逐斩推行法币改革。1937年6月18日, 宋子文等人到广州考察, 认为统一货币时机已经成熟。6月20日，财政部颁布了《改革粤省币制令》，规定从即日起，

27 中国第二历史档案馆编: 《中华民国史档案资料汇编》第5辑第1编 “财政经济” 卷 (4)，江苏古籍出版社1994 年版, 第676-684页; 《整理粤省财政诸要员宋子良等昨晨赴粤》, 《申报》1936年7月23日, 第11版; 《邹琳 宋子良等抵粤》，《申报》1936年7月23日，第3版。

28 《孔祥熙谈整理粤省币制 定三办法即将施行》, 《申报》1936年8月21日, 第3版。

29 许德光: 《改革粤省币制刍议》, 《申报》1936年8月24日, 第14版。

30 《中中交三行运法币至粤》，《申报》1936年8月30日，第11版。

31 颜继金: 《本省币制改革成功》，《四路军月刊》第10期，1937年7月1日，第2页。

32 中国第二历史档案馆编: 《中华民国史档案资料汇编》第5辑第1 编 “财政经济” 卷 (4), 江苏古籍出版社 1994 年版，第691-692页。

33 《改善粤省币制案》, 《申报》1936年8月12日，第9版。

34 《粤桂最近概况 粤省的财政》，《申报》1936年10月3日，第9版。

35 《财政部批复粤市高会电呈》，《申报》1936年8月28日，第9版。

36 《粤省请求修订法币与粤毫券比率》, 《申报》1936年11月10日, 第8版。

37 《省市毫券不得称为法币》, 《广东省政府公报》第341期, 1936年8月30日, 第96页。 
广东省银行、广州市银行所发毫券由中国、中央、交通三银行收回, 广东省银行按法定比率 兄换成国币, 发行准备管理委员会广州分会对还没有收回的毫券应随时保持各有比例的现金 准备。从1937年6月21日起, 毫券以144为法定比率折合国币, 1937年底, 按比率照例使用, 但以国币按照比率来交付的, 不得拒收, 违者严惩。自1938年1月1日起，所有广东省公私款 项及一切买卖交易及契约之收付等各项均以国币为本位, 如再以毫券收付或订立, 在法律上 无效。38这明确规定一切的交易都离不开法币，法币的主体得以确立。1937年6月30日，广东 省财政厅公布了《广东省促进统一办法》，促进法币流通，以形成国家统一货币。1937年8 月23日，鉴于广东法币改革的已经取得的成效，中央财政人员返回南京。

在全国推行法币，统一货币的形势之下，广东本地纸币得以存在并发展，源于广东的半 独立状况。法币政策在广东得以实施, 是在广东归政中央政府后。中央政府在人事上进行安 排，派人员到广东整顿财政，法币在广东由地方“法币”逐渐改革到广东法币。

法币改革是一项金融政策，不是独立的经济问题，受到政治的影响。国民政府1935年推 行示法币改革, 就受到广东当局的变相抵制, 法币在广东困难重重。法币改革在中央政府控 制的地区得以有效推行, 在地方军阀控制的地区则遭受不同程度上的抵抗, 实际上是利益之 争。不只法币改革这样, 其他政策的推行亦如此。1936年两广事变之后, 国民政府对广东当 局进行人事调整, 法币改革在广东才得以真正实施。经过一年多的努力, 法币改革在广东稳 步推进时, 日本的侵略使得法币在广东的改革中止, 直到抗战胜利之后, 法币改革才实现。 只有国家的统一才有货币统一，而货币的统一巩固上国家的统一。

\section{References}

[1] ZhuoZunhong, Modern Chinese Currency Reform, Taibei: National History Museum, 2009.

[2] WangLi, Currency Unification of Kwangtung : A Regional Case Study of the Currency Reform of Nanking Government, Jinan Journal(philosophy and social Sciences) vol.10, pp. 143-151, 2014.

[3] Zhang Xiaojie,The Rise and Fall of Guangdong' s Sliver Voucher, Chinese Coins vol. 3, pp. 13-15, 2014.

[4] Jia Qinhan ,The Dispute over the Cash of Banknotes and the Decision on the Reform of the Legal Currency in 1935, The Journal of Chinese Social and Economic History, vol. 2, pp. 72-81, 2016.

[5] Li jiazhi ,The Active Effect of the Currency Reform in 1935 on the War of Resistance Against Aggression, Journal of Southwest China Normal University(Humanities and social Sciences Edition), vol. 1, pp. 126-129, 2005.

[6] Yang wen ,Legal Currency Reform during the Nationalist Government, Finance Economy,vol. 14, pp. 69-71, 2017.

[7] Wu Jingping, The Decision and Implementation of Chiang Kai-shek and the Legal Currency Policy of 1935, Jiang hai Academic Journal . vol.2, pp. 148-157, 2011.

[8] Xu Feng hua, Review of Legal Currency Reform in the Past 20 Years, Republican Archives.vol.3, pp. 130-138, 2007.

[9] Pan Xiaoxia,The Expectation of Mild Inflation: The Introduction of Fabi policy in 1935, Modern Chinese History Studies. vol.6, pp. 55-68, 2017.

[10]Ye Shichang, Reasons for the Implementation of the Legal Currency Policy and Its Historical Role, Shanghai Economic Review.vol.4, pp. 65-70, 1988.

38 《财部改革瞚省币制令》，《中央银行月报》1937年第6卷第7期，1937年7月，第1416页。 
[11]Yao Huiyuan, On Legal Currency Reform, Academic Monthly.vol.5, pp.55-61, 1997.

[12] Yin Quanzhou, On Chinese Legal Currency Reform, Sociai Sciences In Ningxia.vol.3, pp.34-39, 2001.

[13]Zeng Tao, Before and after the Guangdong unified currency system in the 1930s, Guangdong Financen.vol.10, pp.34-36, 1990. 